\title{
Association between prodynorphin gene polymorphisms and opioid dependence susceptibility: a meta-analysis
}

\author{
Chang-wang Wang ${ }^{1 \dagger}$, Min Ma ${ }^{2 \dagger}$, Wei-guang Lu' and Ru-qin Luo ${ }^{1 *}$
}

\begin{abstract}
Background: Prodynorphin (PDYN) gene polymorphisms have been linked with opioid dependence (OD) with conflicting outcomes, the aim of this study is to synthesize the existing evidence of the association between PDYN polymorphisms and OD susceptibility.

Methods: Four databases including PubMed, EMBASE, Web of Science, and Wanfang were retrieved for relevant studies before August, 2018. All identified studies were evaluated using predetermined inclusion and exclusion criteria. Summary odds ratio (OR) and $95 \%$ confidence interval (95\%Cl) were calculated to appraise the association. Statistical analysis was performed using RevMan 5.3 software.

Results: A total of seven case-control studies with 3129 cases and 3289 controls were recruited in the metaanalysis. For rs910080, rs 1997794, rs 1022563, and rs2235749 polymorphisms of PDYN gene, there were six, four, five, and four studies eventually included, respectively. The findings indicated that $r 5910080$ polymorphism was significantly correlated with $\mathrm{OD}$ among Asian population under allelic model (A vs. G, $O R=1.30,95 \% \mathrm{Cl} 1.04-1.62$, $P=0.02, F D R=0.05$ ) and dominant model ( $A A+A G$ vs. $G G, O R=1.25,95 \% C l 1.04-1.51, P=0.02, F D R=0.05)$. However, rs1022563, rs 1997794 and rs2235749 polymorphisms did not appear to associate with OD susceptibility.

Conclusions: There existed a significant association between rs 1022563 polymorphism and OD among Asian population. As the included studies were not adequate to guarantee a robust and convincing conclusion, future studies with larger sample size among more ethnicities are recommended.
\end{abstract}

Keywords: Prodynorphin, Opioid dependence, Polymorphism, Meta-analysis

\section{Background}

Opioid dependence (OD), mainly characterized by persistent drug-taking and drug-seeking behavior, is a chronic brain disorder that has seriously negative social and health consequences [1]. A range of environmental factors like severe stressors, family separation, divorce, as well as death in the family have been considered to be associated with OD for a long time [2]. However, researchers observe that only a few individuals that were exposed to drugs will finally develop specific addictions [3]. Thus, there are some factors beyond environmental factors that can contribute to OD.

\footnotetext{
* Correspondence: ruqinluo@126.com

${ }^{\dagger}$ Chang-wang Wang and Min Ma contributed equally to this work.

'Department of Psychiatry, Wuchang Hospital, South Luoshi Avenue 505\#,

Hongshan District, Wuhan 430070, China

Full list of author information is available at the end of the article
}

Actually, early in 1990s, the isolation of genes that encoded opioid peptide precursors had opened an era of molecular and genetic investigations of OD [4]. Familybased studies in different countries and regions revealed the heritability estimates for substance dependence of twins ranged from 30 to $70 \%$ [5]. Over the past years, numerous genes and single-nucleotide polymorphisms have been reported to be contributors of OD [6,7].

Prodynorphin (PDYN), also known as preprodynorphin, is the precursor of neoendorphins and dynorphins [8]. The human PDYN gene is mapped to chromosome 20p13 [9]. $P D Y N$ gene knockout mice presented an increasingly explorative behavior in anxiety tests, which demonstrated the role of prodynorphin-derived peptides [10].

Since Zimprich et al. [11] initially reported the correlation between PDYN gene polymorphisms and OD, 
several researchers have subsequently replicated with inconsistent results [12-18]. The lack of convergent findings might ascribe to weak statistical power to ascertain a significant effect, population structure or betweenstudy heterogeneity. Thus, this meta-analysis was conducted to provide a more precise estimation on the relationship of $P D Y N$ gene polymorphisms and OD.

\section{Methods}

The procedures of the systematic review and meta-analysis were conducted in accordance with the Preferred Reporting Items for Systematic Reviews and Meta-Analyses (PRISMA) guidelines [19].

\section{Search strategy of literature}

A systematic search of potentially relevant literature was carried out in PubMed, Web of Science, EMBASE, and Wanfang databases. The following search string was employed: (diamorphine OR opioids OR narcotic OR opium OR opiate OR heroin OR "Heroin"[Mesh]) AND (PDYN OR prodynorphin) AND ("Polymorphism, Single Nucleotide" [Mesh] OR SNP OR mutation OR polymorphism OR variant). No restriction on language was imposed. The search period was set from inception to August, 2018.

\section{Inclusion and exclusion criteria}

Publications that were included in the present study had to satisfy the following criteria: (1) case-control studies looking into the association of PDYN gene polymorphisms and OD; (2) case participants with confirmed diagnosis of OD; (3) studies with sufficient genotype counts to estimate odds ratio (OR) as well as $95 \%$ confidence interval (95\%CI). Accordingly, case-case studies, reviews, conference abstracts, as well as animal studies were excluded.

\section{Quality assessment}

The quality of eligible studies was evaluated separately by two investigators (CW and $\mathrm{MM}$ ) according to Newcastle-Ottawa Scale (NOS). A 'star system' was used to judge the quality of each study on the basis of selection, comparability, as well as exposure. The NOS ranges from zero to nine stars. Studies with five or more stars indicated a high quality.

\section{Data extraction}

The following data were extracted independently by two investigators (CW and $\mathrm{MM}$ ) from each qualified article: author, year of publication, country, ethnicity and gender of participants, sample size, and genotype distribution. Once encountering discrepancies, two authors rechecked the original articles until an agreement was achieved.

\section{Statistical analysis}

Hardy-Weinberg Equilibrium (HWE) [20] of control subjects was calculated. The strength of association of PDYN gene polymorphisms and OD was presented as OR and $95 \% \mathrm{CI}$ in allelic model ( $\mathrm{M}$ vs. W), homozygous model (MM vs. WW), heterozygous model (MW vs. WW), dominant model $(M M+M W$ vs. WW), as well as recessive model (MM vs. $M W+W W)$. To evaluate the heterogeneity across included studies, Qstatistical test alongside $\mathrm{I}^{2}$ test were utilized. $P<0.1$ and $I^{2}>50 \%$ suggested the heterogeneity was not significant, and the fixed-effect model could be applied, otherwise the random-effects model should be employed. Subgroup-analysis by ethnicity was performed to test if there was an ethnicity-specific effect. For multiple testing corrections, the BenjaminiHochberg method was applied to control false discovery rate (FDR) [21]. Forest plots were made by RevMan 5.3 software. Funnel plots were exploited to assess the publication bias.

\section{Results \\ Literature search}

An initial search of four databanks yielded 151 records, of which 44 from Web of Science, 78 from EMBASE, 21 from PubMed, and 8 from Wanfang. Forty-seven records were deleted because of duplication. Ninety-three irrelevant citations were removed from the remaining 104 records after title and abstract screening. Another 4 ineligible articles were erased after comprehensive assessment according to inclusion and exclusion criteria. Ultimately, 7 articles [12-18] were included in qualitative synthesis and meta-analysis. The process was displayed in Fig. 1.

\section{Main characteristics}

The general characteristics of included studies were displayed in Table 1. A total of seven case-control studies [12-18] with 3129 cases and 3289 controls were included in the meta-analysis. Of the included studies, six [12-16, 18] were published in English and one [17] was in Chinese. It should be noted that Clarke et al.'s study [15] published in 2012 consisted of two different cohorts. The sample size of an individual cohort ranged from 119 to 1030 for cases, and 90 to 668 for controls. For $r s 910080$ polymorphism, Hashemi et al.'s study [14] was not in HWE. When it came to rs1022563 polymorphism, three studies [16-18] were out of HWE. As to rs2235749 polymorphism, three studies $[14,16,17]$ were not in HWE. According to NOS, each study received five or more stars (Table 2). 


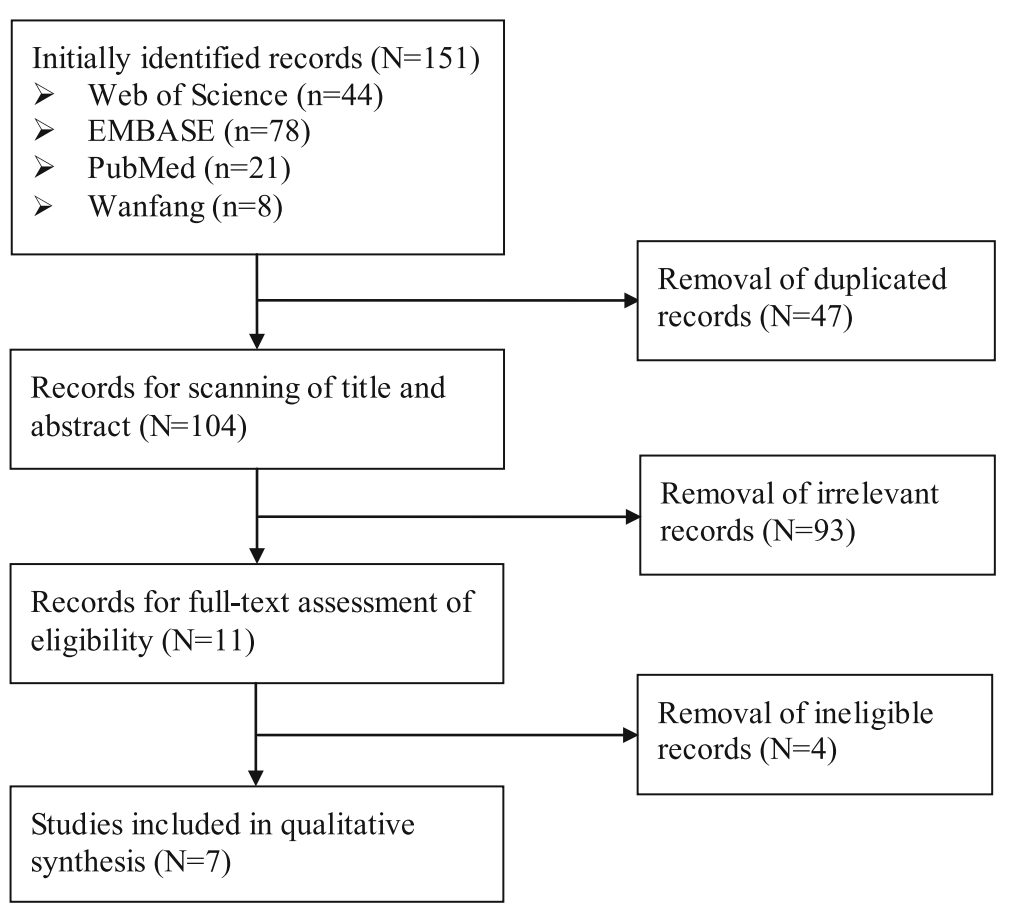

Fig. 1 Flow chart of literature search and screen

\section{Results of meta-analysis}

The correlations of PDYN gene polymorphisms (rs910080, rs1997794, rs1022563, and rs2235749) and OD vulnerability were summarized in Table 3.

Data synthesis for rs910080 was available on six studies [12-17] with seven independent cohorts including 3092 cases and 3136 controls. Due to considerable heterogeneity, random-effect model was employed with the exception of heterozygous model. The pooled data indicated a null correlation between rs 910080 polymorphism and OD susceptibility under five genetic models. Subgroup analysis stratified by ethnicity suggested a significant association between rs910080 polymorphism and OD across Asian population in allelic model (A vs. G, $\mathrm{OR}=1.30,95 \%$ CI $1.04-1.62, P=0.02, \mathrm{FDR}=0.05)$ and dominant models (AA+AG vs. GG, OR $=1.25,95 \% \mathrm{CI}$ 1.04-1.51, $P=0.02$, FDR $=0.05$ ). While no correlation was detected under other models.

As for rs1997794, four studies [12, 13, 15, 18] with five cohorts involving 2942 cases and 2605 controls went into final data synthesis. Because heterogeneity between studies was significant, the random-effect model was applied. The result indicated that rs1997794 polymorphism did not significantly associate with OD in five genetic models. Subgroup analysis stratified by ethnicity also yielded a null association.

In respect of rs1022563, five studies with six cohorts containing 2378 cases and 2400 controls satisfied the eventual data combination. Because of huge heterogeneity, random-effect model was utilized. Rs1022563 polymorphism appeared to have no significant correlation with OD in five genetic models. Subgroup analysis by ethnicity as well indicated a non-significant association.

When it came to $r s 2235749$, four studies [12, 14, 16, 17] with 1273 cases and 1285 controls carried out among Asian population were analyzed. OR and 95\%CI were estimated by the random-effect approach due to significant heterogeneity. The pooled results indicated a null association between rs2235749 polymorphism and OD susceptibility.

\section{Sensitivity analysis and publication bias}

After studies that deviated from HWE were excluded, the corresponding OR did not reverse. Consequently, they were not removed from our meta-analysis. Sensitivity analysis confirmed the stability of the outcomes, where exclusion of individual dataset did not significantly change the overall effects. Furthermore, visual inspection of funnel plots did not identify substantial asymmetry for all the four loci under any genetic model.

\section{Discussion}

OD affects the lives of millions of people worldwide and imposes a heavy burden on society [22]. Hence, seeking new strategies to prevent and treat OD is necessary. Investigation into the etiology of OD has focused on multiple areas. Genetic factors and environmental factors are both considered as contributors to OD. As a genetic 
Table 1 Characteristics of included studies

\begin{tabular}{|c|c|c|c|c|c|c|c|c|c|c|c|c|c|c|c|c|}
\hline \multirow[t]{2}{*}{ Study } & \multirow[t]{2}{*}{ Year } & \multirow[t]{2}{*}{ Country } & \multirow[t]{2}{*}{ Ethnicity } & \multirow[t]{2}{*}{ Gender } & \multirow{2}{*}{$\begin{array}{l}\text { Sample } \\
\text { size }\end{array}$} & \multicolumn{5}{|c|}{ OD (\%) } & \multicolumn{5}{|c|}{ Control (\%) } & \multirow{2}{*}{$\begin{array}{l}\text { HWE } \\
\text { (P-value) }\end{array}$} \\
\hline & & & & & & M & W & MM & MW & WW & M & W & MM & MW & WW & \\
\hline \multicolumn{17}{|l|}{ Rs910080 (A/G) } \\
\hline Yuanyuan et al. & 2018 & China & Asian & Both & $541 / 566$ & 14.3 & 85.7 & 22.2 & 24.2 & 73.6 & 13.2 & 86.8 & 1.6 & 23.1 & 75.3 & 0.77 \\
\hline Nagaya et al. & 2018 & Malaysia & Asian & Male & $459 / 543$ & 16.1 & 83.9 & 34.9 & 25.3 & 71.2 & 12.4 & 87.6 & 2.4 & 20.1 & 77.5 & 0.07 \\
\hline Hashemi et al. & 2018 & Iran & Asian & Both & $216 / 219$ & 43.1 & 56.9 & 19.9 & 46.3 & 33.8 & 30.1 & 69.9 & 3.2 & 53.9 & 52.9 & $<0.01$ \\
\hline Clarke et al. I & 2012 & USA & Caucasian & Both & $1030 / 644$ & 25.0 & 75.0 & 6.0 & 38.0 & 56.0 & 27.6 & 72.4 & 8.9 & 37.6 & 53.6 & 0.12 \\
\hline Clarke et al. II & 2012 & USA & African & Both & $330 / 663$ & 46.8 & 53.2 & 23.0 & 47.6 & 29.4 & 48.2 & 51.8 & 22.8 & 50.8 & 26.4 & 0.64 \\
\hline Wei et al. & 2011 & China & Asian & Both & $304 / 301$ & 21.9 & 78.1 & 4.9 & 33.9 & 61.2 & 15.3 & 84.7 & 1.3 & 27.9 & 70.8 & 0.18 \\
\hline Jia et al. & 2010 & China & Asian & Both & $212 / 200$ & 23.6 & 76.4 & 3.3 & 40.6 & 56.1 & 25.7 & 74.3 & 4.5 & 42.5 & 53.0 & 0.12 \\
\hline \multicolumn{17}{|l|}{ Rs1997794(G/A) } \\
\hline Yuanyuan et al. & 2018 & China & Asian & Both & $541 / 566$ & 16.4 & 83.6 & 2.0 & 28.7 & 69.3 & 15.5 & 84.5 & 1.9 & 27.0 & 71.0 & 0.42 \\
\hline Nagaya et al. & 2018 & Malaysia & Asian & Male & $459 / 543$ & 48.2 & 51.8 & 22.7 & 51.2 & 23.1 & 50.9 & 49.1 & 26.0 & 49.9 & 24.1 & 0.97 \\
\hline Clarke et al. I & 2012 & USA & Caucasian & Both & $1037 / 652$ & 35.0 & 65.0 & 11.7 & 46.6 & 41.8 & 37.9 & 62.1 & 15.3 & 45.1 & 39.6 & 0.28 \\
\hline Clarke et al. II & 2012 & USA & African & Both & $336 / 668$ & 28.3 & 71.7 & 8.6 & 39.3 & 52.1 & 25.1 & 74.9 & 6.3 & 37.6 & 56.1 & 1.00 \\
\hline Clarke et al. & 2009 & China & Asian & Female & $119 / 176$ & 19.3 & 80.7 & 3.4 & 31.9 & 64.7 & 11.4 & 88.6 & 0.6 & 21.6 & 77.8 & 0.34 \\
\hline \multicolumn{17}{|l|}{ Rs1022563(C/T) } \\
\hline Nagaya et al. & 2018 & Malaysia & Asian & Male & $459 / 543$ & 17.9 & 82.1 & 3.9 & 27.9 & 68.2 & 17.6 & 82.4 & 3.3 & 28.6 & 68.1 & 0.72 \\
\hline Clarke et al. I & 2012 & USA & Caucasian & Both & $948 / 644$ & 13.5 & 86.5 & 14.8 & 24.1 & 74.5 & 17.0 & 83.0 & 1.9 & 30.3 & 67.9 & 0.06 \\
\hline Clarke et al. II & 2012 & USA & African & Both & $336 / 660$ & 21.6 & 78.4 & 5.1 & 33.0 & 61.9 & 18.9 & 81.1 & 3.0 & 31.8 & 65.2 & 0.35 \\
\hline Wei et al. & 2011 & China & Asian & Both & $304 / 300$ & 16.3 & 83.7 & 3.9 & 24.7 & 71.4 & 17.0 & 83.0 & 0.7 & 32.7 & 66.7 & $<0.01$ \\
\hline Jia et al. & 2010 & China & Asian & Both & $212 / 90$ & 19.1 & 80.9 & 4.7 & 28.8 & 66.5 & 42.8 & 57.2 & 6.7 & 72.1 & 21.1 & $<0.01$ \\
\hline Clarke et al. & 2009 & China & Asian & Female & $119 / 163$ & 17.6 & 82.4 & 5.9 & 23.5 & 70.6 & 13.8 & 86.2 & 0 & 27.6 & 72.4 & 0.04 \\
\hline \multicolumn{17}{|l|}{ Rs2235749(T/C) } \\
\hline Yuanyuan et al. & 2018 & China & Asian & Both & $541 / 566$ & 15.2 & 84.8 & 2.4 & 25.5 & 72.1 & 13.5 & 86.5 & 19.4 & 23.1 & 74.9 & 0.81 \\
\hline Hashemi et al. & 2018 & Iran & Asian & Both & $216 / 219$ & 38.2 & 61.8 & 7.9 & 60.6 & 31.5 & 37.2 & 62.8 & 4.1 & 66.2 & 29.7 & $<0.01$ \\
\hline Wei et al. & 2011 & China & Asian & Both & $304 / 300$ & 21.9 & 78.1 & 5.3 & 33.2 & 61.5 & 15.3 & 84.7 & 1 & 28.7 & 70.3 & 0.07 \\
\hline Jia et al. & 2010 & China & Asian & Both & $212 / 200$ & 18.6 & 81.4 & 4.7 & 27.8 & 67.5 & 27.3 & 72.8 & 14 & 26.5 & 59.5 & $<0.01$ \\
\hline
\end{tabular}

$O D$ opioid dependence, $M$ mutant allele, $W$ wild allele, HWE Hardy-Weinberg Equilibrium

Table 2 Quality of included studies

\begin{tabular}{|c|c|c|c|c|c|c|c|}
\hline Item/Study & $\begin{array}{l}\text { Nagaya et al. } \\
2018 \text { [13] }\end{array}$ & $\begin{array}{l}\text { Hashemi et al. } \\
2018[14]\end{array}$ & $\begin{array}{l}\text { Clarke et al. } \\
2012[15]\end{array}$ & $\begin{array}{l}\text { Wei et al. } \\
2011[16]\end{array}$ & $\begin{array}{l}\text { Jia et } \\
\text { al. } \\
2010 \\
{[17]}\end{array}$ & $\begin{array}{l}\text { Clarke et al. } \\
2009[18]\end{array}$ & $\begin{array}{l}\text { Yuanyuan et al. } \\
2018 \text { [12] }\end{array}$ \\
\hline Adequate definition of cases & $\star$ & $\star$ & $\star$ & $\star$ & $\star$ & $\star$ & $\star$ \\
\hline Representativeness of cases & ts & $\sum$ & 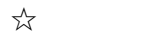 & 论 & $\sum$ & $i$ & $\sum$ \\
\hline Selection of control subjects & $\sum$ & $\dot{s}$ & $i$ & $\hat{s}$ & $\sum\langle$ & $i$ & $\sum$ \\
\hline Definition of control subjects & $\star$ & $\star$ & $\star$ & $\star$ & $\star$ & $\star$ & $\star$ \\
\hline $\begin{array}{l}\text { Control for important factor or } \\
\text { additional factor }\end{array}$ & $\star \Sigma$ & $\star \Sigma$ & $\star \Sigma$ & $\star \Sigma$ & 论坛 & 论坛 & $\star \lesssim$ \\
\hline Exposure assessment & $\star$ & $\star$ & $\star$ & $\star$ & $\star$ & $\star$ & $\star$ \\
\hline $\begin{array}{l}\text { Same method of ascertainment } \\
\text { for all subjects }\end{array}$ & $\star$ & $\star$ & $\star$ & $\star$ & $\star$ & $\star$ & $\star$ \\
\hline Non-response rate & $\star$ & $\star$ & $\star$ & $\star$ & $\star$ & $\star$ & $\star$ \\
\hline
\end{tabular}

$\star$, a star given; $亡$, a star not given 
Table 3 Association between prodynorphin gene polymorphisms and opioid dependence

\begin{tabular}{|c|c|c|c|c|c|c|c|}
\hline \multirow[t]{2}{*}{ Genetic model } & \multicolumn{3}{|c|}{ Association } & \multirow[t]{2}{*}{ FDR } & \multirow{2}{*}{$\begin{array}{l}\text { Effect } \\
\text { model }\end{array}$} & \multicolumn{2}{|c|}{ Heterogeneity } \\
\hline & $\overline{\mathrm{OR}}$ & $95 \% \mathrm{Cl}$ & $P$-value & & & $\overline{P(\%)}$ & $P$-value \\
\hline \multicolumn{8}{|l|}{ Rs910080 } \\
\hline \multicolumn{8}{|l|}{ Overall } \\
\hline A vs. G & 1.16 & $0.94-1.41$ & 0.16 & 0.28 & $\mathrm{R}$ & 81 & $<0.01$ \\
\hline AA vs. GG & 1.53 & $0.83-2.84$ & 0.17 & 0.28 & $\mathrm{R}$ & 84 & $<0.01$ \\
\hline AG vs. GG & 1.06 & $0.95-1.19$ & 0.32 & 0.32 & $F$ & 32 & 0.18 \\
\hline$A A+A G$ vs. GG & 1.12 & $0.93-1.34$ & 0.24 & 0.30 & $\mathrm{R}$ & 63 & 0.01 \\
\hline$A A$ vs. $A G+G G$ & 1.52 & $0.85-2.70$ & 0.16 & 0.28 & $\mathrm{R}$ & 83 & $<0.01$ \\
\hline \multicolumn{8}{|l|}{ Asian } \\
\hline A vs. G & 1.30 & $1.04-1.62$ & 0.02 & 0.05 & $\mathrm{R}$ & 70 & 0.01 \\
\hline AA vs. GG & 2.21 & $0.96-5.09$ & 0.06 & 0.07 & $\mathrm{R}$ & 76 & $<0.01$ \\
\hline AG vs. GG & 1.17 & $1.01-1.36$ & 0.04 & 0.07 & $F$ & 7 & 0.37 \\
\hline$A A+A G$ vs. GG & 1.25 & $1.04-1.51$ & 0.02 & 0.05 & $F$ & 40 & 0.15 \\
\hline$A A$ vs. $A G+G G$ & 2.13 & $0.94-4.83$ & 0.07 & 0.07 & $\mathrm{R}$ & 76 & $<0.01$ \\
\hline \multicolumn{8}{|l|}{ Rs1997794 } \\
\hline \multicolumn{8}{|l|}{ Overall } \\
\hline G vs. A & 1.02 & $0.85-1.22$ & 0.87 & 0.94 & $\mathrm{R}$ & 72 & 0.01 \\
\hline GG vs. AA & 0.98 & $0.68-1.43$ & 0.94 & 0.94 & $\mathrm{R}$ & 58 & 0.05 \\
\hline GA vs. AA & 1.06 & $0.94-1.20$ & 0.36 & 0.94 & $\mathrm{~F}$ & 20 & 0.29 \\
\hline$G G+G A$ vs. $A A$ & 1.07 & $0.89-1.30$ & 0.46 & 0.94 & $\mathrm{R}$ & 55 & 0.06 \\
\hline GG vs. $G A+A A$ & 0.95 & $0.69-1.31$ & 0.77 & 0.94 & $\mathrm{R}$ & 52 & 0.08 \\
\hline \multicolumn{8}{|l|}{ Asian } \\
\hline G vs. A & 1.06 & $0.76-1.46$ & 0.74 & 0.74 & $\mathrm{R}$ & 78 & 0.01 \\
\hline GG vs. AA & 0.90 & $0.65-1.23$ & 0.50 & 0.63 & $\mathrm{~F}$ & 49 & 0.14 \\
\hline GA vs. AA & 1.10 & $0.91-1.32$ & 0.34 & 0.63 & $\mathrm{R}$ & 51 & 0.13 \\
\hline $\mathrm{GG}+\mathrm{GA}$ vs. $\mathrm{AA}$ & 1.16 & $0.82-1.63$ & 0.41 & 0.63 & $\mathrm{R}$ & 68 & 0.04 \\
\hline GG vs. $G A+A A$ & 0.89 & $0.68-1.17$ & 0.41 & 0.63 & $F$ & 39 & 0.20 \\
\hline \multicolumn{8}{|l|}{ Rs1022563 } \\
\hline \multicolumn{8}{|l|}{ Overall } \\
\hline C vs. T & 0.85 & $0.62-1.17$ & 0.32 & 0.40 & $\mathrm{R}$ & 88 & $<0.01$ \\
\hline CC vs. TT & 1.29 & $0.57-2.89$ & 0.54 & 0.54 & $\mathrm{R}$ & 75 & $<0.01$ \\
\hline CT vs. TT & 0.66 & $0.44-1.00$ & 0.05 & 0.25 & $\mathrm{R}$ & 89 & $<0.01$ \\
\hline$C C+C T$ vs. TT & 0.71 & $0.47-1.07$ & 0.11 & 0.28 & $\mathrm{R}$ & 89 & $<0.01$ \\
\hline$C C$ vs. $C T+\pi T$ & 1.45 & $0.79-2.65$ & 0.23 & 0.38 & $\mathrm{R}$ & 57 & 0.04 \\
\hline \multicolumn{8}{|l|}{ Asian } \\
\hline C vs. T & 0.80 & $0.47-1.37$ & 0.42 & 0.50 & $\mathrm{R}$ & 91 & $<0.01$ \\
\hline CC vs. TT & 1.71 & $0.36-8.07$ & 0.50 & 0.50 & $\mathrm{R}$ & 83 & $<0.01$ \\
\hline CT vs. TT & 0.54 & $0.26-1.13$ & 0.10 & 0.35 & $\mathrm{R}$ & 92 & $<0.01$ \\
\hline$C C+C T$ vs. TT & 0.60 & $0.29-1.25$ & 0.17 & 0.35 & $\mathrm{R}$ & 93 & $<0.01$ \\
\hline$C C$ vs. $C T+\pi T$ & 2. 04 & $0.66-6.27$ & 0.21 & 0.35 & $\mathrm{R}$ & 69 & 0.02 \\
\hline \multicolumn{8}{|l|}{ Rs2235749 } \\
\hline T vs. C & 1.04 & $0.74-1.46$ & 0.83 & 0.83 & $\mathrm{R}$ & 83 & $<0.01$ \\
\hline TT vs. CC & 1.34 & $0.42-4.25$ & 0.62 & 0.83 & $\mathrm{R}$ & 85 & $<0.01$ \\
\hline TC vs. CC & 1.09 & $0.92-1.30$ & 0.32 & 0.83 & $\mathrm{~F}$ & 2 & 0.38 \\
\hline
\end{tabular}


Table 3 Association between prodynorphin gene polymorphisms and opioid dependence (Continued)

\begin{tabular}{|c|c|c|c|c|c|c|c|}
\hline \multirow[t]{2}{*}{ Genetic model } & \multicolumn{3}{|c|}{ Association } & \multirow[t]{2}{*}{ FDR } & \multirow{2}{*}{$\begin{array}{l}\text { Effect } \\
\text { model }\end{array}$} & \multicolumn{2}{|c|}{ Heterogeneity } \\
\hline & $\overline{\mathrm{OR}}$ & $95 \% \mathrm{Cl}$ & $P$-value & & & $\overline{P^{2}(\%)}$ & $P$-value \\
\hline$T+\mathrm{TC}$ vs. CC & 1.05 & $0.78-1.41$ & 0.75 & 0.83 & $R$ & 64 & 0.02 \\
\hline$\pi$ vs. $T C+C C$ & 1.34 & $0.43-4.16$ & 0.61 & 0.83 & $\mathrm{R}$ & 85 & $<0.01$ \\
\hline
\end{tabular}

$S N P$ single nucleotide polymorphism, $O R$ odds ratio, $C l$ confidence interval, $F$ fix-effect model, $R$ random-effect model, $F D R$ adjusted $P$-value for false discovery rate

factor, $P D Y N$ gene has received more and more attention [23].

Several studies across different populations have been performed on the association of $P D Y N$ gene polymorphisms and OD vulnerability, while it is quite regrettable that no convincing evidence is available. This inconsistency could be interpreted by several factors, including severity of diagnosis, limited sample size, inadequate power, ethnic heterogeneity, population stratification, as well as large phenotype range. The present study, with pooled data from Asian (Malaysia, Iran, and China), Caucasian (European American), and African (African American) populations, indicated that $r s 910080$ polymorphism was significantly correlated with OD among Asian population. However, rs1022563, rs1997794 and rs2235749 polymorphisms did not appear to associate with OD susceptibility.

$P D Y N$ gene codes ligand of opioid receptor. Functional variant in $P D Y N$ gene hampers the downstream signaling pathway and affects the overall biological networks, thus implicating in the pathophysiology of OD. Dynorphins are a cluster of posttranslational products of PDYN gene. They bind to all three types of opiate receptors, but exhibit considerable affinity to kappa opioid receptor [24]. Products of PDYN gene have been reported to inhibit neurotransmission and take part in mood regulation, stress responses [25], reward [26], and motor functions. Yuferov et al. [27] reported the mRNA of PDYN was rich in brain areas that were associated with drug-taking and drug-withdrawal. Wang et al. [28] found that acute intermittent morphine administration could raise $P D Y N$ and kappa opioid receptor mRNA level in the brains of rat models. Solecki et al. [29] observed that chronic exposure to heroin could lead to an increased PDYN mRNA in the nucleus accumbens shell and core of rats. All this evidence suggested that PDYN gene played a crucial role in the occurrence and development of OD.

Heterogeneity is a crucial issue when elucidating the outcomes of a meta-analysis. We attempted to minimize this issue by developing strict criteria for study inclusion, information extraction, as well as data analysis. Considerable heterogeneity between studies still existed despite subgroup analysis was stratified. Several potential reasons might give rise to the presence of heterogeneity. For demographics, age of individual study ranges greatly.
For gender, although majority studies are mixed genders, some are focusing on only men or women. For genetic background, included studies are multi-national and many ethnic groups were represented within them. For environmental factor, participants from both developing countries and developed countries were incorporated into the present study.

\section{Study limitations}

Although the current study has collected available data on the association between PDYN gene polymorphisms and OD predisposition, several limitations could not be neglected. First, the present outcomes were based on unadjusted estimates. Because raw data for confounding factors like age [30], gender [15], socioeconomic status [31] of the participants were unavailable, we could not perform the corresponding stratification analysis. Second, the number of participants of each included study was limited, thus lacking enough statistic power to guarantee the association. Third, we only investigated the role of four independent polymorphisms in PDYN gene. However, finding susceptibility polymorphisms and genes was a difficult task owing to the intricate mode of inheritance and multiple polymorphisms in various genes contributing to increased disease risk. OD, without exception, is a multifactor disorder determined by the synthetic effects and interactions of a series of polymorphisms, genes, and environmental factors. These interactions might conceal or enlarge the function of the included polymorphisms. Lastly, only seven articles from four databanks were searched for this study, potentially relevant studies published in other databanks might be missed.

\section{Conclusion}

Taken together, the current study indicated the $r s 910080$ polymorphism was significantly correlated with OD among Asian population. However, rs1022563, rs1997794 and rs2235749 polymorphisms did not appear to associate with OD susceptibility. Due to limitations demonstrated above, the associations between $P D Y N$ gene polymorphisms and the risk of OD could not be entirely concluded. As the included studies were not adequate to guarantee a robust and convincing conclusion, studies with larger sample size among more populations are recommended. 


\section{Abbreviations}

Cls: Confidence interval; HWE: Hardy-Weinberg equilibrium; NOS: NewcastleOttawa Scale; OD: Opioid dependence; ORs: Odds ratios; PDYN: prodynorphin

\section{Acknowledgements}

Not applicable.

\section{Authors' contributions}

$R L$ designed the study. CW and MM were responsible for collection of data and performing the statistical analysis and manuscript preparation. CW and WL were responsible for checking the data. All authors were responsible for drafting the manuscript, read and approved the final version.

\section{Funding}

Not applicable.

\section{Availability of data and materials}

The datasets used and/or analyzed during the current study are available from the corresponding author Ru-qin Luo, ruqinluo@126.com.

\section{Ethics approval and consent to participate}

Not applicable.

\section{Consent for publication}

Not applicable.

\section{Competing interests}

The authors declare that they have no competing interests.

\section{Author details}

'Department of Psychiatry, Wuchang Hospital, South Luoshi Avenue 505\#, Hongshan District, Wuhan 430070, China. '2Department of Anesthesiology, Zhongnan Hospital of Wuhan University, Wuhan 430071, China.

Received: 18 September 2018 Accepted: 4 September 2019 Published online: 11 September 2019

\section{References}

1. Cami J, Farre M. Drug addiction. N Engl J Med. 2003;349(10):975-86.

2. Tyrfingsson $T$, Thorgeirsson $T E$, Geller $F$, Runarsdottir $V$, Hansdottir I, Bjornsdottir G, et al. Addictions and their familiality in Iceland. Ann N Y Acad Sci. 2010;1187:208-17.

3. Trigo JM, Martin-Garcia E, Berrendero F, Robledo P, Maldonado R. The endogenous opioid system: a common substrate in drug addiction. Drug Alcohol Depend. 2010;108(3):183-94.

4. Charbogne P, Kieffer BL, Befort K. 15 years of genetic approaches in vivo for addiction research: Opioid receptor and peptide gene knockout in mouse models of drug abuse. Neuropharmacology. 2014:76(Pt B):204-17.

5. Agrawal A, Lynskey MT. Are there genetic influences on addiction: evidence from family, adoption and twin studies. Addiction. 2008;103(7):1069-81.

6. Prom-Wormley EC, Ebejer J, Dick DM, Bowers MS. The genetic epidemiology of substance use disorder: a review. Drug Alcohol Depend. 2017;180:241-59.

7. Goldman D, Oroszi G, Ducci F. The genetics of addictions: uncovering the genes. Nat Rev Genet. 2005;6(7):521-32.

8. Yuferov V, Levran O, Proudnikov D, Nielsen DA, Kreek MJ. Search for genetic markers and functional variants involved in the development of opiate and cocaine addiction and treatment. Ann N Y Acad Sci. 2010;1187:184-207.

9. Litt M, Buroker NE, Kondoleon S, Douglass J, Liston D, Sheehy R, et al. Chromosomal localization of the human proenkephalin and prodynorphin genes. Am J Hum Genet. 1988;42(2):327-34.

10. Wittmann W, Schunk E, Rosskothen I, Gaburro S, Singewald N, Herzog H, et al. Prodynorphin-derived peptides are critical modulators of anxiety and regulate neurochemistry and corticosterone. Neuropsychopharmacology. 2009;34(3):775-85.

11. Zimprich A, Kraus J, Woltje M, Mayer P, Rauch E, Hollt V. An allelic variation in the human prodynorphin gene promoter alters stimulus-induced expression. J Neurochem. 2000;74(2):472-7.

12. Yuanyuan J, Rui S, Hua T, Jingjing C, Cuola D, Yuhui S, et al. Genetic association analyses and meta-analysis of Dynorphin-kappa opioid system potential functional variants with heroin dependence. Neurosci Lett. 2018; 685:75-82.
13. Nagaya D, Zahari Z, Saleem M, Yahaya BH, Tan SC, Yusoff NM. An analysis of genetic association in opioid dependence susceptibility. J Clin Pharm Ther. 2018;43(1):80-6.

14. Hashemi M, Shakiba M, Sanaei S, Shahkar G, Rezaei M, Mojahed A, et al. Evaluation of prodynorphin gene polymorphisms and their association with heroin addiction in a sample of the southeast Iranian population. Mol Biol Res Commun. 2018;7(1):1-6.

15. Clarke TK, Ambrose-Lanci L, Ferraro TN, Berrettini WH, Kampman KM, Dackis CA, et al. Genetic association analyses of PDYN polymorphisms with heroin and cocaine addiction. Genes Brain Behav. 2012;11(4):415-23.

16. Wei SG, Zhu YS, Lai JH, Xue HX, Chai ZQ, Li SB. Association between heroin dependence and prodynorphin gene polymorphisms. Brain Res Bull. 2011; 85(3-4):238-42.

17. Jia W, Sh JG, Ao L, Lei A, Zhang R. Association between polymorphism in $3^{\prime}$ untranslated regions of prodynorphin gene and heroin dependence. Progress Modern Biomed. 2010;10(13):2439-41.

18. Clarke TK, Krause K, Li T, Schumann G. An association of prodynorphin polymorphisms and opioid dependence in females in a Chinese population. Addict Biol. 2009:14(3):366-70.

19. Moher D, Liberati A, Tetzlaff J, Altman DG. Preferred reporting items for systematic reviews and meta-analyses: the PRISMA statement. BMJ. 2009; 339:b2535.

20. Ryckman K, Williams SM. Calculation and use of the Hardy-Weinberg model in association studies. Curr Protoc Hum Genet. 2008:Chapter 1:Unit 1.18.

21. Benjamini Y, Yekutieli D. Quantitative trait loci analysis using the false discovery rate. Genetics. 2005:171(2):783-90.

22. Darcq E, Kieffer BL. Opioid receptors: drivers to addiction? Nat Rev Neurosci. 2018;19(8):499-514.

23. Reed B, Butelman ER, Yuferov V, Randesi M, Kreek MJ. Genetics of opiate addiction. Curr Psychiatry Rep. 2014;16(11):504.

24. Schwarzer C. 30 years of dynorphins--new insights on their functions in neuropsychiatric diseases. Pharmacol Ther. 2009;123(3):353-70.

25. Drolet G, Dumont EC, Gosselin I, Kinkead R, Laforest S, Trottier JF. Role of endogenous opioid system in the regulation of the stress response. Prog Neuro-Psychopharmacol Biol Psychiatry. 2001;25(4):729-41.

26. Kelley AE, Bakshi VP, Haber SN, Steininger TL, Will MJ, Zhang M. Opioid modulation of taste hedonics within the ventral striatum. Physiol Behav. 2002;76(3):365-77

27. Yuferov VP, Laforge KS, Spangler R, Maggos CE, Kreek MJ. Guinea pig preprodynorphin $\mathrm{mRNA}$ : primary structure and regional quantitation in the brain. DNA Cell Biol. 1996;15(12):1105-12.

28. Wang XM, Zhou Y, Spangler R, Ho A, Han JS, Kreek MJ. Acute intermittent morphine increases preprodynorphin and kappa opioid receptor mRNA levels in the rat brain. Brain Res Mol Brain Res. 1999:66(1-2):184-7.

29. Solecki W, Ziolkowska B, Krowka T, Gieryk A, Filip M, Przewlocki R. Alterations of prodynorphin gene expression in the rat mesocorticolimbic system during heroin self-administration. Brain Res. 2009;1255:113-21.

30. Yuferov V, Randesi M, Butelman ER, van den Brink W, Blanken P, van Ree JM, et al. Association of variants of prodynorphin promoter 68-bp repeats in caucasians with opioid dependence diagnosis: effect on age trajectory of heroin use. Neurosci Lett. 2019;704:100-5.

31. Pear VA, Ponicki WR, Gaidus A, Keyes KM, Martins SS, Fink DS, et al. Urbanrural variation in the socioeconomic determinants of opioid overdose. Drug Alcohol Depend. 2019;195:66-73.

\section{Publisher's Note}

Springer Nature remains neutral with regard to jurisdictional claims in published maps and institutional affiliations. 